\title{
Determining the working status of the production organization structure in the mechanized longwall when the negative impact factor has appeared
}

\author{
Hung Phi Nguyen* \\ Faculty of Mining, Hanoi University of Mining and Geology, Vietnam
}

\section{ARTICLE INFO \\ Article history: \\ Received $11^{\text {th }}$ Sept. 2020 \\ Revised 28 $8^{\text {th }}$ Nov. 2020 \\ Accepted $31^{\text {st }}$ Dec. 2020}

Keywords:

Geology factors,

Longwall mechanized,

Potential impact factor,

Production organization

structure,

Technical factors.
ABSTRACT

For the purpose of ensuring sustainable development, one of the important factors is to increase labor productivity and minimize the number of workers directly working in the mine. In the context of increasing requirements for underground coal mining, the number of workers tends to decline due to shifting to other types of economy. Therefore, the mechanization investment in coal mining is the inevitable destination, which guarantees the long - term strategic development of the coal mining industry. Although the mechanized mining has obtained several achievements, the annual coal mining output is still not high, specifically reaching 73.8\%; 51.3\%; 61.4\% according to the plan respectively for the years of 2013, 2014 and 2015. A total of mechanized lines has been invested and applied in Vietnam National Coal - Mineral Industries Holding Corporation Limited, but there are only six lines in operation until at this time. For five recent years, when the mining industry has accumulated a lot of experience in using mechanization technology, it is found that the potential factors causing production interruption have resulted in the effectiveness of these longwalls not achieved as expected. Summary of advantages, difficulties, and unsuccessful implementation of mechanization technology in the condition of Quang Ninh mine area has shown a big gap in production organization that should be specifically studying. In this study, the author wants to build a basic background in determining the impact of potential factors conscious of the longwall mechanized.
${ }^{*}$ Corresponding author

E - mail: nguyenphihung@humg.edu.vn

DOI: 10.46326/JMES.2020.61(6).02
1. Production organization model of the fully mechanized longwall

1.1. An overview of some production organization models of the fully mechanized longwall 
The production organization structure reflects the rationality in terms of space and time, the ability to coordinate among people with the operating system and equipment. The production organization structure of the mechanized longwall depends heavily on the type of technology being used. Currently, according to the technology used for longwall mining, it can be divided into two basic groups: a group of longwalls with lowering the roof coal ceiling and another group of longwalls without ceiling lowering.

The model of production organization for the mechanized longwall is divided into two types including four shifts per day - night and three shifts per day - night.

The organizational model of four shifts per day - night is based on the division and arrangement of labor in a day and night into four separate shifts, the time of each shift may be the same of different, but basically can be divided into four equally shifts with six hours per shift. Depending on the workload of each shift, the corresponding number of labor shall be arranged. Typically, the organizational model of four shifts per day - night usually focuses on producing in the first three shifts, while the fourth shift is used to inspect, repair and maintain equipment (Figure 1). Equipment inspection and maintenance does not necessarily occur at the last shift every day. This work depends on the actual situation of the mine, mainly related to the operational status of the equipment and the number of labor assigned.

In essence, the production arrangement between the organizational models of three shifts per day - night and four shifts per day - night does not make much difference. The focus on production and periodic shear is usually arranged in the first shift, while the inspection and maintenance of equipment occurs at the end of the cycle.

The difference between the two types of mechanized technology with and/or ceiling lowering in the recovery of the coal on the roof that the shearer cannot fully cut. The recovery work accounts for a relatively large proportion of time in the overall production cycle. Recovery time depends on the recovery organization method.

For the mechanized longwall with ceiling lowering for coal recovery, the organizational model of 3 shifts/day - night is applied, in which the production is usually arranged in the first 2 shifts, while the third shift is used for inspection and maintenance (Figure 2). In some cases, the lowering of the coal ceiling can be performed separately in the third shift in addition to equipment maintenance.

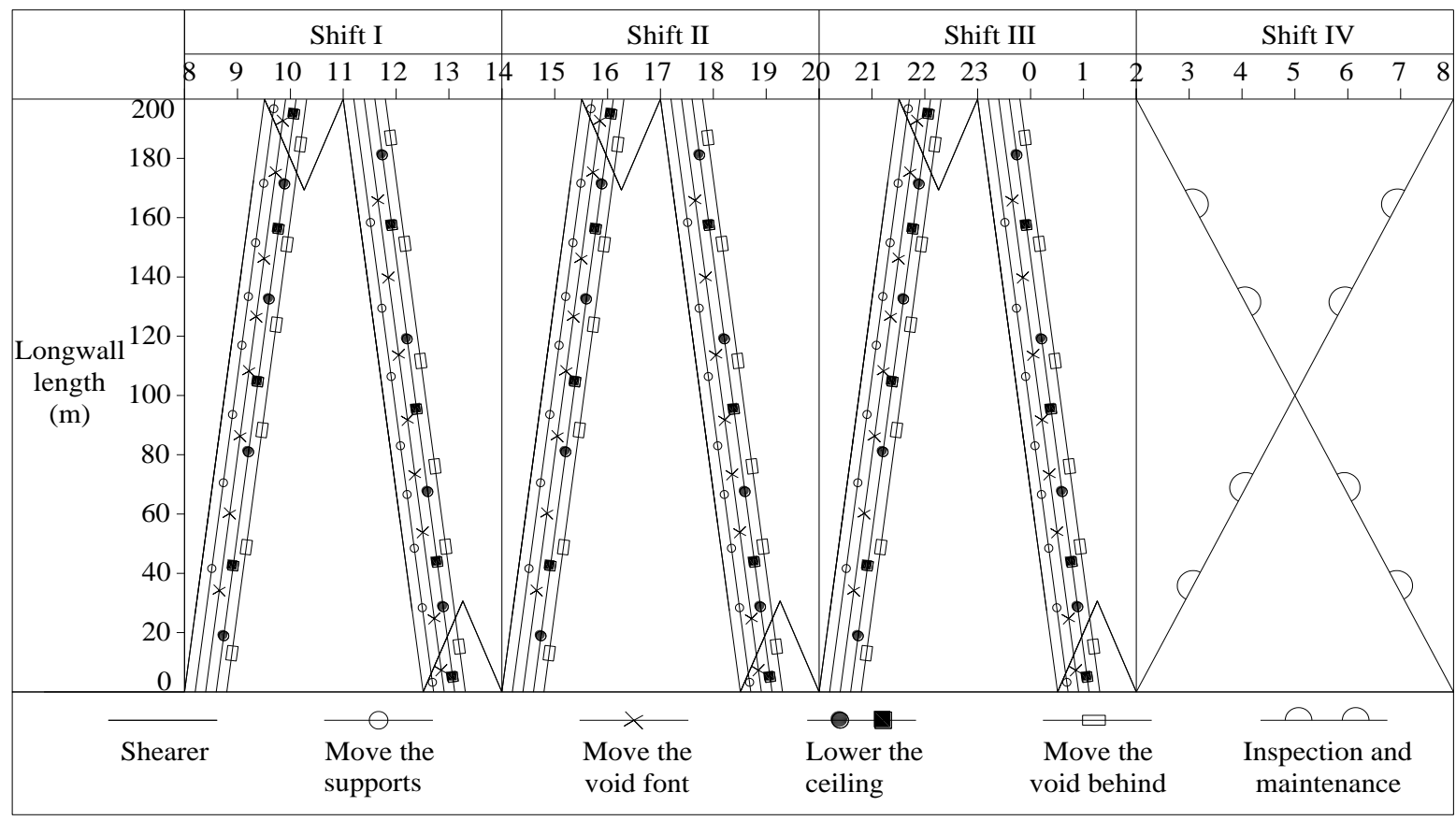

Figure 1. Production organization chart of 04 shifts/day - night (Yun et al., 2003). 
Time and workload of each production shift is designed in accordance with the actual conditions of the production unit (Nguyen et al., 2019). Therefore, in some specific cases, the duration of shifts may not be equal, while the inspection and maintenance of equipment is not necessarily at the end of the production cycle. This makes the production model more flexible, improving production efficiency.

The difference in the time of organizing the cycle or allocating production manpower among mechanized longwall mines is mainly in the stage of examining and recovering coal on the lower ceiling. Depending on the thickness of the lower layer of coal, the work of lowering the ceiling may take a long time, affecting the performance of subsequent production stages in the longwall production cycle.

Considered objectively, the work of mechanizing longwall mines in Vietnam often lags behind the advanced coal industry in the world. The application of mechaniztion in longwall mining in Vetnam has been mainly inherited with adjustments from experiences in other developed countries. The model of actual production organization in mechanized longwall mines in Vietnam is arranged according to the general organizational model of Vietnam's coal industry, which is 3 shifts/day - night. The shift from 3 shifts/day - night to 4 shifts/day - night did not occur.

Due to the geological characteristics of coal mines in Vietnam, the planning of production organization in each shift depends on the actual production conditions in the area of the mechanized longwall. The workload in each shift may be similar or different. Equipment inspection and maintenance may be arranged at the end of the cycle or at the beginning of each production shift.

All models of production organization both in the world and in the country have not considered the potential risks such as geological conditions of mines, technology, equipment, etc., causing production interruptions. The production arrangement at each unit has been adjusted to suit the actual conditions corresponding to each specific time. However, the work of determining the production organization structure, establishing production organization charts or human resource organization charts often does not keep up with reality, because it does not take into account the disadvantages arising from natural conditions, engineering, technology, leading to poor flexibility and lack of initiative in the initial production structure.

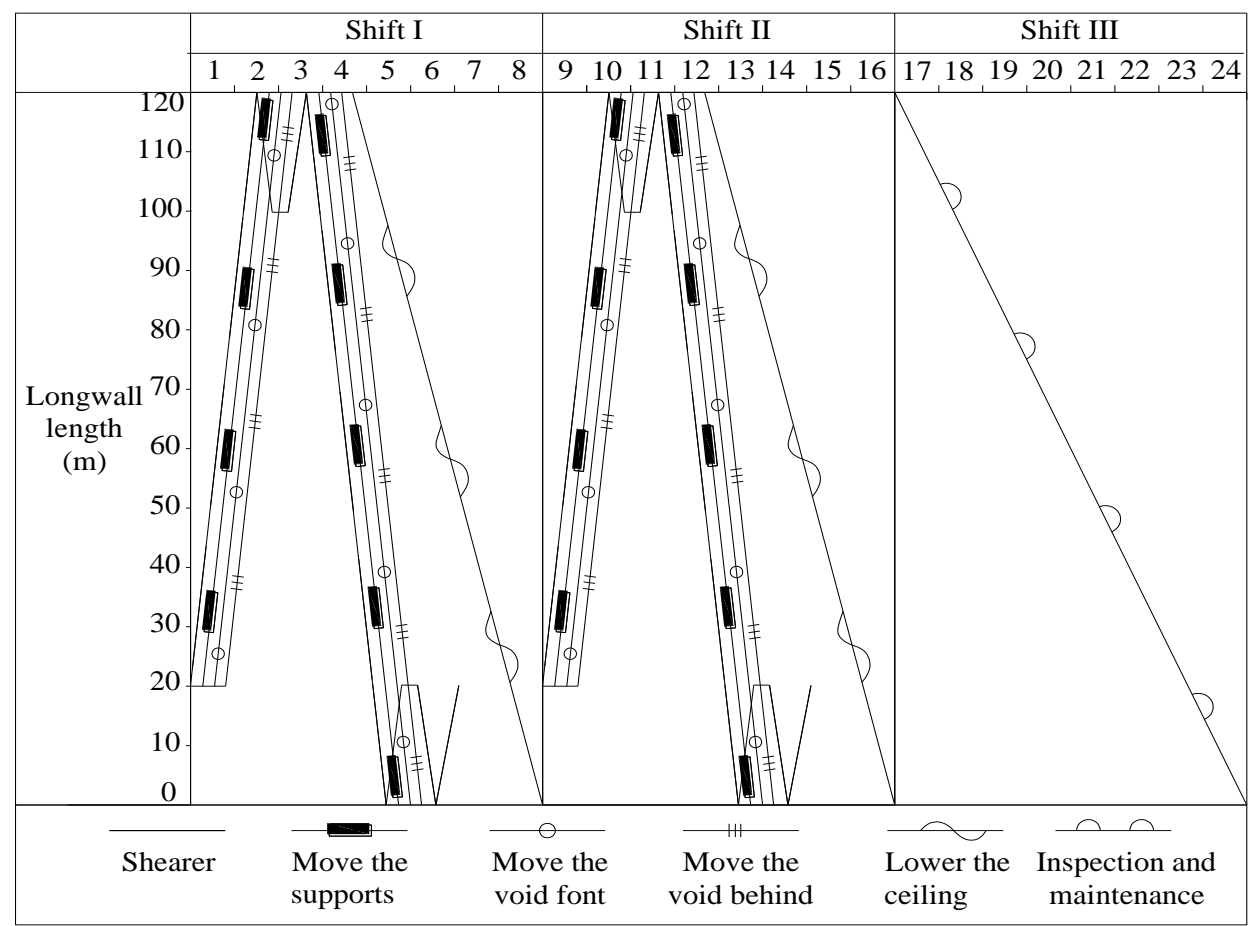

Figure 2. Organizational chart of the longwall cycle 8402 at Xishui coal mine, China (Yun et al., 2003). 


\subsection{An overview of reseach on the production organization structure of the mechanized longwall}

Research on the production organization structure is for the factors that constitute the production organization of the mechanized longwall. Researches on the production organization structure have been carried out by domestic and foreign scientists with the aim of establishing a reasonable production organization structure, improving the efficiency and productivity of all stages in the process of mechanized longwall production.

In Vietnam, for describing a production cycle in the longwall and the number of manpower needed to serve that area, organizations and businesses are currently using two common methods: forward calculation method and reverse calculation method. In the world, there are also 02 most popular methods to evaluate the possibility of applying mechanized mining technology diagrams in underground mines: Method of scoring and method of general assessment of coal reserves and geological characteristics - mining techniques. Besides, there are studies conducted by scientists in countries with developed coal mining industries that are meant to lay the groundwork for research on production organization structure, and symptotic studies with the development trends of modern mining industry of other scientists.

Although there have been many researches works to solve the problem of building the production organizatin structure for the mechanized longwall in the world, most of them have been done for static conditions, have not yet mobilized to calculate the influencing factors in dynamic and variablie conditions of the mechanized longwall (Wang et al., 2019; Yun et al., 2003). The research methods of production organization have certain advantages, depending on the conditions that can be used, resulting in relatively reliable results. In general, however, these production organization methods, in one way or another, have not yet comprehensively assessed the influencing factors (inputs). Thus, the production organization according to the plan always maintains a certain difference compared to the reality, especially with the specific conditions in the underground mines in Vietnam.
For the purpose of gradually completing the production organization method, it is necessary to study practical shortcomings, directly affecting the efficiency of production organization.

- The production organization models in the mechanized longwall are basically geared towards continuity in the production line. There are two models of working arrangement encompassing a model of working three shifts per day - night and another model of working four shifts per day - night. In the world the two models may be interchangeable or they themselves will improve continuous operation in many shifts and maintenance pushed back to the next shift, while the model of three shifts per day - night is arranged in Vietnam.

- The deviation between the design and the actual construction of the mechanized longwall in Quang Ninh shows that the potential risk of production interruption has not been properly assessed in accordance with the level of influence. Especially, unexplored geological conditions and mining techniques are the main causes affecting the unsucessful mechanized longwalls in our country.

- The role of the organizational structure of mechanized longwall production is to regulate the exploitation activities in accordance with the specific conditions. There is no specific work in the world and in the country to study and establish the organizational structure of mechanized longwall production in Quang Ninh, which is also a space to develop its research.

\section{The impact of mining geology and techniques on the organizational structure of mechanized longwall production}

\subsection{Impact of mining geology on mechanization technology for underground coal mining}

Assessing the longwall mining technology is an integrated assessment of many factors and layers. The basis of the integrated assessment is to measure the dependence of geological factors on the mechanized longwall mines. From there it forms a basis for establishing an integrated assesment model.

The study has applied Fuzzy evaluation method to develop the dependent functions of 
geological factors impacting on the mechanized longwall mine, depicting the influence of these factors on the mining work (Snopkowski and Sukiennik, 2013). The geological factors are divided into 3 basic groups encompassing a group directly related to the coal seam, a group related to the rock surrounding the seam and another group related to technical factors.

Based on domestic and global practical experience in mechanization technology, the method of hierarchical analysis is applied to determine the importance of factors where the different factors are different effect values (see
Table 1) (Vayenas and Yuriy, 2007; Nguyen et al., 2019).

Determining the influence of mining geology on the mechanized longwall helps to develop an algorithm diagram to select the appropriate equipment according to geological and technical conditions (Figure 3).

The first factor to consider whether the production structure can be operated is the suitability of the mechanized longwall equipment combination with the natural conditions of the mining area.

Table 1. Summary of the factors affecting the mechanized longwall mining.

\begin{tabular}{|c|c|c|c|c|c|c|}
\hline No. & Factors & $\begin{array}{l}\text { Total value in } \\
\text { normal mechani - } \\
\text { zation }\end{array}$ & $\begin{array}{l}\text { Total value in } \\
\text { lower - ceiling } \\
\text { mechanization }\end{array}$ & Factors & $\begin{array}{l}\text { Normal } \\
\text { mechani } \\
\text { - zation }\end{array}$ & $\begin{array}{l}\text { Lower - } \\
\text { ceiling } \\
\text { mechani - } \\
\text { zation }\end{array}$ \\
\hline \multirow[b]{2}{*}{1} & \multirow{2}{*}{$\begin{array}{l}\text { Complexity } \\
\text { of structural } \\
\text { geology }\end{array}$} & \multirow[b]{2}{*}{0.2076} & \multirow[b]{2}{*}{0.1968} & 1. Effect of interruption & 0.1428 & 0.1503 \\
\hline & & & & 2. Effect of folds & 0.0648 & 0.0465 \\
\hline \multirow{3}{*}{2} & \multirow{3}{*}{$\begin{array}{l}\text { Degree of } \\
\text { stability of } \\
\text { coal seam }\end{array}$} & \multirow{3}{*}{0.2387} & \multirow{3}{*}{0.2418} & $\begin{array}{l}\text { 1. Mining capacity of coal } \\
\text { seam }\end{array}$ & 0.1098 & 0.1012 \\
\hline & & & & $\begin{array}{ll}2 . \quad \text { Fluctuation } & \text { of } \\
\text { thickness }\end{array}$ & 0.0862 & 0.0028 \\
\hline & & & & $\begin{array}{l}\text { 3. Coefficient of hard } \\
\text { rock content }\end{array}$ & 0.0427 & 0.1378 \\
\hline 3 & $\begin{array}{l}\text { Seam } \\
\text { thickness }\end{array}$ & 0.0937 & 0.1045 & $\begin{array}{l}\text { Depth of the coal seam } \\
\text { mining }\end{array}$ & 0.0937 & 0.1043 \\
\hline 4 & $\begin{array}{ll}\text { Seam slope } \\
\text { angle }\end{array}$ & 0.1049 & 0.1321 & Steep angle of coal seam & 0.1049 & 0.1321 \\
\hline 5 & $\begin{array}{l}\text { Seam } \\
\text { strength }\end{array}$ & 0.0211 & 0.1436 & Seam strength & 0.0211 & 0.1436 \\
\hline \multirow{4}{*}{6} & \multirow{4}{*}{$\mid \begin{array}{ll}\text { Conditions } \\
\text { of } & \text { stone } \\
\text { panel } & \end{array}$} & \multirow{4}{*}{0.2135} & \multirow{4}{*}{0.0867} & $\begin{array}{l}\text { 1. Stability of direct } \\
\text { panel }\end{array}$ & 0.1008 & 0.0307 \\
\hline & & & & $\begin{array}{l}\text { 2. Reciprocity of basic } \\
\text { panel }\end{array}$ & 0.0792 & 0.0322 \\
\hline & & & & 3. Effect of fake panel & 0.0091 & 0.0034 \\
\hline & & & & 4. Impact of pillar & 0.0244 & 0.0204 \\
\hline \multirow{2}{*}{7} & \multirow{2}{*}{$\begin{array}{l}\text { Longwall } \\
\text { speed }\end{array}$} & \multirow{2}{*}{0.1205} & \multirow{2}{*}{0.0945} & 1. Longwall length & 0.0646 & 0.0536 \\
\hline & & & & 2. Length in the direction & 0.0659 & 0.0409 \\
\hline 8 & Total & 1.000 & 1.000 & Total & 1.000 & 1.000 \\
\hline
\end{tabular}




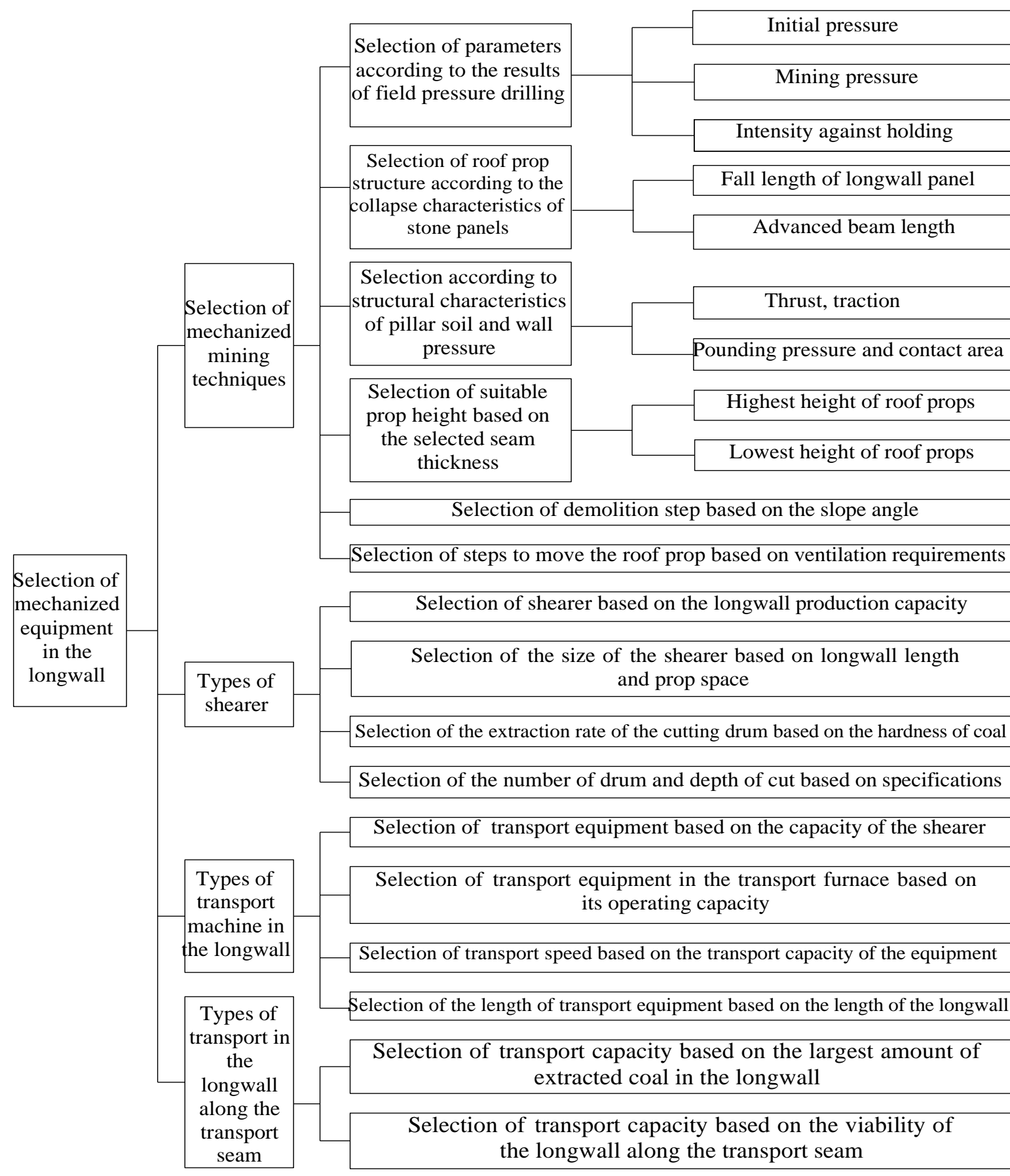

Figure 3. Block diagram of selecting a combination of equipment suitable to geological and technical conditions.

\subsection{Analysis of the impact of mining technical conditions on the production organization structure}

The operational mode of the production organization structure depends not only on geological conditions but also on the suitability of exploitation system, preparation system, and a system of features of the equipment combination.

The compatibility relationship of equipment combination in the longwall space includes shearer - void - prop, while the relationship between the production capacity of the mechanzied longway and equipment serving 
outside the longway plays an esspecially important role in forming the production organization structure suitable for longwall mines. The ability to operate continuously and the compatibility between the combination of longwall equipment are critical to the working efficiency of the organizational structure of mechanized longwall production.

\section{Working status of the production organization structure when taking into account adverse impacts from mining geological and technical conditions}

The operational mode of the longwall equipment combination is divided into two main equipment groups: extraction equipment group and support equipment group.

For extraction equipment (shearers), there are different forms of work depending on the location of space, time and technological factors selected. The form of extraction is usually divided into one - way and two - way extraction, in which there is a clear difference between the processes of open - cut extraction (examination) and pattern extraction. Nowadays, most mechanized longway mines use mainly two - drum shearers, two - way coal shearers in order to avoid empty operation and have high operating efficiency. The examination of the mechanized longwall is relatively complicated, requires a large number of workers and low technical content, which is one of the main factors affecting the productivity and efficiency of the mechanized longwall.

For support equipment (props), their form of operation is basically the way the props move. In the mechanized longwall, the work of moving props is divided into three types: a type of movement in turn for support, a type of alternating movement and another type of group movement. The mode of movement in turn for support of the longwall depends on factors such as shearer speed, top and bottom panel conditions, flow of emulsion pump stations. Often the travel speed of support must meet the speed requirement of the shearer, which is a rule for choosing how to move the support.

For the longwall with lowering the ceiling for roof coal recovery, the effectiveness of the aforementioned combination of operating equipment is highly dependent on the ceiling lowering distance and the way to lower the coal ceiling. Experiments show that the application of the method of two - stream extraction with ceiling lowering in multiple turns for the mechanized longway mining, brings the highest percentage of roof coal recovery.

While taking into account the suitability of a selected equipment combination in terms of geological conditions, technical space and compatibility in the workspace, it is required to consider the potential negative factors affecting the production organization structure.

The fact that the operation of a longwall mine is convenient or difficult, depends a lot on potential factors from mining geological conditions, technology techniques and other impacts. The state of the factors, whether directly or indirectly, in the adverse direction may cause interruption or reduce the longwall productivity.

There are $n$ factors that may cause production interruption. State 0 is considered that all factors affecting the mechanized longwall do not negatively affect, and the organizational structure operates normally. State $\mathrm{j}$ is the jth part which is in a state of adverse effect on the structure. At that time, the diagram will change from the status to be restored and corrected to the normal operating state as shown in Figure 4.

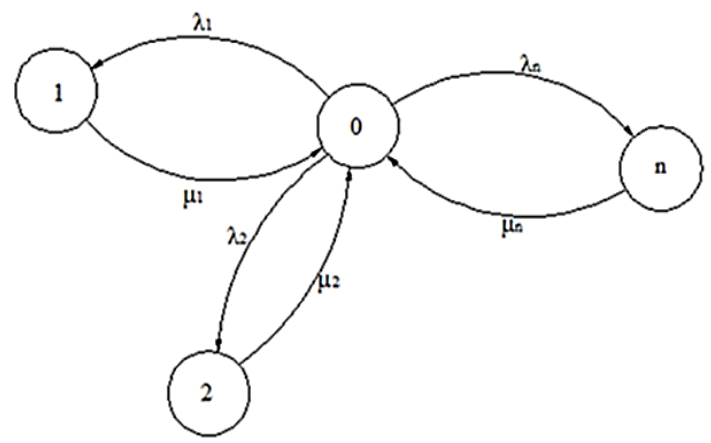

Figure 4. Diagram of the change in the state of the production organization structure when it has a negative impact.

Where: $\lambda_{j}$ - Frequency of malfunction of the jth part; $\mu_{j}$ - Ability to repair and restore the jth error to state 0 ;

The probability of transitioning from state $\mathrm{j}$ to state 0 depends on the fixed - state orientation parameter $\pi=\left(\pi_{0}, \pi_{1}, \ldots, \pi_{n}\right)$, when turning negative states into a normal operating state, it means that: 


$$
\left\{\begin{array}{c}
-\lambda . \pi_{0}+\mu_{1} \cdot \pi_{1}+\cdots+\mu_{n} \cdot \pi_{n}=0 \\
\lambda_{1} \cdot \pi_{0}-\mu_{1} \cdot \pi_{1}=0 \\
\cdots \\
\lambda_{n} \cdot \pi_{0}-\mu_{n} \cdot \pi_{n}=0
\end{array}\right.
$$

The above expression shows that in oder to return to the normal operating state (state 0 ), the multivariate functions of the risk of interruption must be zero.

\section{Conclusion and discussion}

1. The natural conditions (mining geological conditions) are unchangeable objective. The technical specifications, technology, preparation system, ancillary others, etc... of the mechanized longwall mine should be built on the basis of suitability with the geological conditions of the mine. It was found that the geological conditions determine, directly or indirectly, the operational mode of the production organization structure of the mechanized longwall.

2. The ability to operate continuously and the compatibility between the combination of longwall equipment is critical to the working efficiency of the production organization structure of the mechanized longwall.

3. Space, time, performance and continuity of the production organization structure are affected by unidentifiable underlying factors. When the underlying factors appear and cause negative effects as disrupted production, it is necessary to activate the recovery mode $\mu$ j. Waiting time for transitioning from interruption to normal operation is called work - time wait.

\section{References}

Nguyen, P. H., Nguyen V. D. and Vu, T. T. D, (2019). Develop a method to determine the effective working time based on the potential factors of mechanized longwall. Journal of Mining and Earth Sciences 4, 19 - 23 (In Vietnamese).

Nguyen, V. D., Vu, T. T. D., Dao, V. C., Bui, M. T., Nguyen, P. H., Vu, T. Q. and Dinh, T. T. N., (2019). Setup knotting model to determine influencing factors and effective working time in the organizational structure of mechanized longwall production. Journal of Mining and Earth Sciences 60(5), 31 - 37 (In Vietnamese).

Snopkowski, R. and Sukiennik, M., (2013). Longwall Face Crew Selection with Respect to Stochastic Character of the Production Process. Archives of Mining Sciences 58, 227 240.

Vayenas, N. and Yuriy, G., (2007). Using GenRel for reliability assessment of mining equipment. Journal of Quality in Maintenance Engineering 13(1), 62 - 74.

Wang, G. F., Xu, Y. X. and Ren, H. W., (2019). Intelligent and ecological coal mining as well as clean utilization technology in China: Review and prospects. International Journal of Mining Science and Technology 29(2), 161 - 169.

Yun, Q. X., Guo, W. W., Chen, Y. F., Lu, C. W. and Lian, M. J., (2003). Evolutionary algorithms for the optimization of production planning in underground mines. Application of Computers and Operations Research in the Minerals Industries, 311 - 314. 